\title{
Diabetic neuropathy: the future is promising. Reply to Uusitupa M, Niskanen L, Laitinen T [letter] and Coppini DV [letter]
}

\author{
Brian C. Callaghan ${ }^{1,2}$ (D) $\cdot$ Gary Gallagher $^{1} \cdot$ Vera Fridman $^{3} \cdot$ Eva L. Feldman $^{1}$
}

Received: 22 June 2020 / Accepted: 22 June 2020 / Published online: 17 July 2020

(C) Springer-Verlag GmbH Germany, part of Springer Nature 2020

Keywords Diabetic neuropathy $\cdot$ Diagnostic testing $\cdot$ Exercise $\cdot$ Obesity $\cdot$ Prediabetes

\section{Abbreviation \\ MNSI Michigan Neuropathy Screening Instrument}

To the Editor: We appreciate the comments by Uusitupa et al [1] and David Coppini [2] pertaining to our recent article in Diabetologia: 'Diabetic neuropathy: what does the future hold?' [3]. We agree that hyperglycaemia is important in individuals with type 2 diabetes. Hyperglycaemia is the number one risk factor for diabetic complications, including diabetic neuropathy [4]. However, we were emphasising the surprising lack of a large effect of more aggressive control of hyperglycaemia in the prevention of neuropathy in populations with type 2 diabetes. Despite including multiple large clinical trials involving a large number of participants that were followed for long periods of time, a meta-analysis did not demonstrate a statistically significant reduction in the incidence of neuropathy in those with enhanced glycaemic control [5]. The effect was minor and consistent across studies, with an approximately 5\% reduction in neuropathy incidence. Therefore, better glycaemic control is likely to be important for the prevention of diabetic neuropathy, but the effect is small, and other factors are also likely important. We hypothesise that obesity and other metabolic risk factors are likely to play an important role in the pathogenesis of diabetic neuropathy and need to be addressed to prevent neuropathy in this population. Obesity has emerged as the second most

Eva L. Feldman

efeldman@med.umich.edu

1 Department of Neurology, University of Michigan, 109 Zina Pitcher Place, 4021 BSRB, Ann Arbor, MI 48104, USA

2 Veterans Affairs Healthcare System, Ann Arbor, MI, USA

3 Department of Neurology, University of Colorado, Denver, CO, USA important risk factor for neuropathy and interventions to target this risk factor should be further pursued [4, 6-10].

We also agree that cardiovascular autonomic neuropathy is an important complication of diabetes, but this topic was beyond the scope of our recent review [3]. We have demonstrated that central obesity, but not general obesity, is associated with somatic and cardiovascular autonomic neuropathy [11]. This implies that central obesity is important in the pathogenesis of both conditions. Whether this finding is replicated in other populations will be important to guide future interventions.

Moreover, we concur with Uusitupa et al [1] that diet and exercise are promising therapies for the prevention and treatment of somatic and cardiovascular autonomic neuropathy. In the Action for Health and Diabetes (Look AHEAD) study, an obese population with type 2 diabetes $(N=5145)$ was randomised to a lifestyle weight-loss intervention or usual care. The intervention resulted in improvements on the Michigan Neuropathy Screening Instrument (MNSI) questionnaire after 9-11 years of the intervention [12]. We are currently conducting a randomised clinical trial to compare high intensity interval training with routine care in those with and without bariatric surgery. The goal is to determine the effects of exercise, weight-loss surgery and their combination on somatic and cardiovascular autonomic neuropathy outcomes. Dr Coppini argues that weight loss and exercise should be instituted in individuals with diabetes regardless of their effect on neuropathy outcomes [2]. While true, weight loss and exercise are both life-altering lifestyle changes; therefore, understanding which is more important for the health of peripheral nerves is essential. Furthermore, the amount of resources dedicated towards weight loss and exercise needs to be determined given the costs associated with certain implementations of these interventions.

Dr Coppini makes the point that the diagnosis of neuropathy is not straightforward in the clinical setting [2]. We agree that the myriad of diagnostic tests available for neuropathy can be confusing. Currently, the best confirmatory tests for 
neuropathy are nerve conduction studies and skin biopsies for intraepidermal nerve-fibre density. However, most individuals only require a detailed history and neurological examination, especially given the expense and discomfort of the two 'confirmatory' options. Therefore, confirmatory tests should be reserved for those with atypical features, such as asymmetry, acute/subacute onset, non-length dependence and/or motor predominance. Dr Coppini provides evidence supporting artificial-intelligence systems utilising corneal confocal microscopy [2]. This diagnostic test shows promise, but much more work is needed before this approach becomes ready for routine clinical use. Corneal confocal microscopy has been shown in a multi-centre study to have only decent diagnostic characteristics [13]. Artificial-intelligence systems are an interesting approach, but will only be as good as the information available for statistical analysis. The AUC for this approach $(\mathrm{AUC}=0.83)$ is comparable with that of the MNSI questionnaire $(\mathrm{AUC}=0.75)$ and examination $(\mathrm{AUC}=0.81)$ [14], which are both much easier and cheaper to administer. The American Diabetes Association currently states that diagnostic testing for diabetic neuropathy should usually stop after a detailed clinical history, neurological examination and routine laboratory tests [15]. Confirmatory tests that are superior to nerve conduction studies and skin biopsies are needed, but require vigorous testing prior to clinical implementation.

Dr Coppini also describes multiple negative clinical trials in neuropathy treatments [2]. These negative results only further emphasise the need for novel disease-modifying therapies for the prevention and treatment of neuropathy. We provide data to support further efforts to target dyslipidaemia and sphingolipids [3]. Hopefully, these pathways will provide the desperately needed new neuropathy medications but, if not, this should not discourage researchers from pursuing other potential mechanisms given the high prevalence and morbidity of neuropathy. Dr Coppini also recommends focusing efforts on prediabetes (impaired fasting glucose and impaired glucose tolerance) and prevention of neuropathy, rather than on treatment of already established neuropathy [2]. Given that prevention of nerve injury has been easier than its reversal, this suggestion has merit and we wholeheartedly agree. Hopefully, the future will lead to treatments that can both prevent and reverse nerve injury. Until that time, researchers should focus on both possibilities with an emphasis on prevention.

Authors' relationships and activities BCC consults for a PCORI grant and for DynaMed and performs medical legal consultations including consultations for the Vaccine Injury Compensation Program. ELF consults for Novartis. GG and VF declare that there are no relationships or activities that might bias, or be perceived to bias, their work.

Contribution statement All authors were responsible for drafting the article and revising it critically for important intellectual content. All authors approved the version to be published.

\section{References}

1. Uusitupa M, Niskanen L, Laitinen T (2020) Divergent pathologies and treatment options for diabetic neuropathies. Diabetologia. https://doi.org/10.1007/s00125-020-05226-0

2. Coppini DV (2020) Diabetic neuropathy: are we still barking up the wrong tree and is change finally in sight? Diabetologia. https://doi. org/10.1007/s00125-020-05231-3

3. Callaghan BC, Gallagher G, Fridman V, Feldman EL (2020) Diabetic neuropathy: what does the future hold? Diabetologia 63: 891-897. https://doi.org/10.1007/s00125-020-05085-9

4. Callaghan BC, Xia R, Reynolds E et al (2016) Association between metabolic syndrome components and polyneuropathy in an obese population. JAMA Neurol 73(12):1468-1476. https://doi.org/10. 1001/jamaneurol.2016.3745

5. Callaghan BC, Little AA, Feldman EL, Hughes RA (2012) Enhanced glucose control for preventing and treating diabetic neuropathy. Cochrane Database Syst Rev Issue 6, Art. No.: CD007543. https://doi.org/10.1002/14651858.CD007543.pub2.

6. Andersen ST, Witte DR, Dalsgaard EM et al (2018) Risk factors for incident diabetic polyneuropathy in a cohort with screen-detected type 2 diabetes followed for 13 years: ADDITION-Denmark. Diabetes Care 41(5):1068-1075. https://doi.org/10.2337/dc172062

7. Callaghan BC, Gao L, Li Y et al (2018) Diabetes and obesity are the main metabolic drivers of peripheral neuropathy. Ann Clin Transl Neurol 5(4):397-405. https://doi.org/10.1002/acn3.531

8. Callaghan BC, Xia R, Banerjee M et al (2016) Metabolic syndrome components are associated with symptomatic polyneuropathy independent of glycemic status. Diabetes Care 39(5):801-807. https:// doi.org/10.2337/dc16-0081

9. Hanewinckel R, Drenthen J, Ligthart S et al (2016) Metabolic syndrome is related to polyneuropathy and impaired peripheral nerve function: a prospective population-based cohort study. J Neurol Neurosurg Psychiatry 87(12):1336-1342. https://doi.org/ 10.1136/jnnp-2016-314171

10. Schlesinger S, Herder C, Kannenberg JM et al (2019) General and abdominal obesity and incident distal sensorimotor polyneuropathy: insights into inflammatory biomarkers as potential mediators in the KORA F4/FF4 cohort. Diabetes Care 42(2):240 247. https://doi.org/10.2337/dc18-1842

11. Callaghan BC, Reynolds EL, Banerjee M et al (2020) The prevalence and determinants of cognitive deficits and traditional diabetic complications in the severely obese. Diabetes Care. https://doi.org/ $10.2337 / \mathrm{dc} 19-1642$

12. The Look AHEAD Research Group (2017) Effects of a long-term lifestyle modification programme on peripheral neuropathy in overweight or obese adults with type 2 diabetes: the Look AHEAD study. Diabetologia 60(6):980-988. https://doi.org/10.1007/ s00125-017-4253-z

13. Perkins BA, Lovblom LE, Bril V et al (2018) Corneal confocal microscopy for identification of diabetic sensorimotor polyneuropathy: a pooled multinational consortium study. Diabetologia 61(8):1856-1861. https://doi.org/10.1007/s00125018-4653-8

14. Callaghan BC, Xia R, Reynolds E et al (2018) Better diagnostic accuracy of neuropathy in obesity: a new challenge for neurologists. Clin Neurophysiol 129(3):654-662. https://doi.org/10.1016/j. clinph.2018.01.003

15. Pop-Busui R, Boulton AJ, Feldman EL et al (2017) Diabetic neuropathy: a position statement by the American Diabetes Association. Diabetes Care 40(1):136-154

Publisher's note Springer Nature remains neutral with regard to jurisdictional claims in published maps and institutional affiliations. 